\title{
A Challenging in Diagnosis of Mucous Membrane Pemphigoid with Desquamative Gingivitis Presentation: A Case Report
}

\author{
Maryam Koopaie $e^{1, *}$ \\ ${ }^{1}$ Department of Oral Medicine, School of Dentistry, Tehran University of Medical Sciences, Tehran, Iran \\ "Corresponding author: Maryam Koopaie, Tehran University of Medical Sciences, International Campus, School of Dentistry, Tehran, Iran. Tel: +98-2188351150, E-mail: \\ m-koopaie@tums.ac.ir
}

Received 2017 November 28; Revised 2018 March 12; Accepted 2018 March 18.

\begin{abstract}
Desquamative gingivitis (DG) is a descriptive term, indicating inflamed and peeling gingiva. It is characterized by sloughing of the gingival epithelium as a result of formation and rupture of the vesicle. Consequently, the gingiva appears erythematous and often edematous. Desquamative gingivitis may represent an oral clinical manifestation of various systemic mucocutaneous diseases. This case report is on a 42-year-old female with chief complaint of burning sensation in the anterior maxillary gingiva. The patient did not have any other lesion at other sites of the oral cavity. The patient had been affected by asthma and her medications were salbutamol spray and tab cetirizine. Clinically, anterior gingiva appeared as the presentation of desquamative gingivitis. Therefore, an incisional biopsy of the affected area for histopathologic assessment and an incisional biopsy of clinically normal-appearing gingiva for direct immunofluorescence(DIF) study were performed. The histopathologic report was herpes simplex infection. However, this report was incompatible with the clinical view and the patient history. Therefore, a second biopsy was performed. The second histopathologic report was compatible with MMP. The treatment plan was local corticosteroid with follow-up. At the one-month examination visit, a significant improvement was observed in the clinical view of the gums.
\end{abstract}

Keywords: Desquamative Gingivitis (DG), Mucous Membrane Pemphigoid (MMP), Direct Immunofluorescence (DIF)

\section{Introduction}

Mucous membrane pemphigoid (MMP) is a chronic autoimmune subepithelial disease that primarily affects the mucous membranes of patients older than 50 years of age, leading to mucosal blistering, ulceration, and resultant scarring in some organs. The disease occurs twice as frequently in females than males. The first lesion of MMP occurs once autoantibodies, directed against proteins within the basement membrane zone, acting with complement (C3), cause a subepithelial split and resultant vesicle formation. Antibodies against basement membrane antigens are known in cases of MMP (1-3). Lesions of MMP could involve any mucosal surface, however, the oral mucosa is involved in more than $80 \%$ of cases, seldom with scarring. The conjunctiva is the second most common site of involvement and might result in scarring and adhesions developing between the palpebral and bulbar conjunctiva, known as symblepharon (4-6).

Biopsy specimens should be taken for both routine and direct immunofluorescent (DIF) studies in patients with MMP. The biopsy for routine histology and DIF should be taken from the vesicle, edge of an ulcer, or erythema and tissue. Histopathology discloses sub-epithelial clefting with preservation of variable inflammation (7). In the DIF technique, MMP patient's biopsy specimens illustrate positive DIF studies for IgG, C3, and often IgA in 50\% to $80 \%$ of cases. Management of MMP relies upon the severity and site of involvement. When the lesions are confined to the oral mucosa, use of systemic corticosteroids should be considered for short periods until steroid-sparing therapy can be instituted $(3,8)$.

Desquamative gingivitis (DG) is a descriptive term, indicating inflamed, fiery red, and peeling gingiva. Formation and rupture of a vesicle results in sloughing of the gingival epithelium. Consequently, the gingiva appears erythematous and often edematous. The patient's chief complaint is a burning sensation, pain, and spontaneous bleeding gums. Presence of dental plaque can aggravate the symptom of DG. Desquamative gingivitis is a clinical, non-pathognomonic term rather than a distinct diagnosis and may represent the oral clinical manifestation of various systemic mucocutaneous diseases. These include mucous membrane pemphigoid, pemphigus vulgaris or lichen planus (9). 


\section{Case Presentation}

The patient, a 42-year-old female, presented to the oral Medicine department of Tehran University of Medical Sciences. The patients' chief complaint was a burning sensation of the maxillary gingiva for about 6 months. The buccal aspect of the maxillary marginal and attached gingiva was erythematous and sloughing (Figure 1). There was no associated ocular, cutaneous, and genital lesion. In her medical history, the patient had asthma and consumed salbutamol spray 3 times a day and cetirizine q24 hours. The patient's oral hygiene was poor because of difficulty in brushing, and bleeding on probing was positive. On the examination of gingiva, Nikolsky's sign was negative. The other areas of her mouth were healthy. Based on the clinical pattern, differential diagnosis included mucous membrane pemphigoid, pemphigus vulgaris, bullous pemphigoid, and bullous lichen planus.

After taking informed consent from the patient, given the desquamative pattern of the gingiva, an incisional biopsy of the affected area and its healthy periphery was taken. Another biopsy was taken from the healthy gingiva for the assessment by DIF studies. The reported histopathology was HSV infection. Stratified squamous epithelium with focal ulceration replaced by fibrino leukocytic exudates associated with extensive adjacent epithelial cell necrosis and acantholysis with herpes simplex virus (HSV) related cytopathic changes including ground glass nuclei, nuclear modeling and few multinucleated giant cells.

Because of the 6-month duration of the disease and its chronic pattern, HSV diagnosis was incompatible with the clinical pattern; thus, a blind review by another oral pathologist was performed. Furthermore, HSV was diagnosed based on histopathologic features. Another biopsy from the affected gingiva and surrounding healthy tissue was taken. Before repeating the biopsy, scaling and root planning of the gingiva was done in order to prevent the effect of inflammation on the biopsy examination.

In the second biopsy, histopathological features were compatible with mucous membrane pemphigoid. Microscopic examination showed a mucosal lesion composed of epithelial tissue, separated from the underlying connective tissue. Mild to moderate chronic inflammatory cells infiltration containing prominent plasma cells, lymphocytes, and intermixed with scattered neutrophils in the superficial connective tissue were also seen (Figure 2) yet the DIF study was negative for IgM, IgA and IgG in MMP. The DIF results were double checked to confirm proper diagnosis and prevent pathologist mistakes.

Based on the results, treatment was initiated with topical corticosteroid (triamcinolone acetonide $0.1 \%$ ointment in orabase (Teriadent, RAHA pharmaceutical Co., Iran) 3 times per day)) and nystatin solution 100000 U/ML (Emad Darman Pars Co., Iran). The patient was followed every 2 weeks for the first 1 month. The lesions improved considerably with topical steroids within 2 weeks from starting the treatment. The frequency of topical steroid application was tapered to once daily application for the next 10 days. Due to the frequent use of corticosteroid and the risk of candidial infection, nystatin was prescribed for the next 2 weeks of the treatment. Nystatin starts with the onset of corticosteroid treatment when potent topical steroid is used. A fungal infection may emerge and a parallel treatment with antifungal drugs may be necessary when the number of applications exceeds once a day. After the 1-year follow up, no recurrence was observed. In Figure 3, the comparison of the patient's gingiva before (Figure $3 \mathrm{~A}$ ) and after (Figure 3B) treatment is shown.

\section{Discussion}

One of the typical clinical appearances of mucocutaneous diseases is desquamative gingivitis (10). Most cases of DG are known to be due to mucocutaneous conditions, like pemphigus, lichen planus, and pemphigoid. Other causes include allergic reactions to toothpastes/mouth rinses (plasma cell gingivitis), Crohn's disease, psoriasis, and chronic ulcerative stomatitis. Desquamative gingivitis can be misdiagnosed with gingivitis and can lead to mistake in diagnosis and improper treatment of lifethreatening dermatological diseases like pemphigus (1113). Mucous Membrane Pemphigoid is a chronic autoimmune subepithelial disease that mainly affects mucous membranes of the body. The oral cavity is the first site or the only site of MMP involvement. The oral cavity's lesions are seen in almost all reported cases and in $48 \%$ of patients, oral cavity is the first site of involvement. When there is oral lesion, gingival involvement is seen in $100 \%$ of cases $(1,14)$.

The prevalence of disease in females is twice that of males. It affects patients that are older than 50 years. The primary lesion of MMP occurs when autoantibodies directed against proteins in the basement membrane zone, acting with complement (C3), cause a subepithelial split and subsequent vesicle formation. Antibodies against basement membrane antigens have been identified in cases of MMP(3).

In this case, the most challenging part was the histopathological features that were not compatible with clinical appearances. The problem was that at the time of biopsy examination, there was asymptomatic shedding of HSV in the oral cavity, which influences the histopathological feature and results in mistakes in the diagnosis. Fur- 


\begin{tabular}{|c|c|c|c|c|c|c|}
\hline $\begin{array}{l}\text { Study References/ } \\
\text { year }\end{array}$ & Age $(y) / \operatorname{Sex}$ & Nikolsky's Sign & Diagnosis & Oral Lesion & DIF & Treatment \\
\hline$(16) / 2010$ & $60 / M$ & Positive & $\begin{array}{l}\text { Benign mucous } \\
\text { membrane } \\
\text { pemphigoid (BMMP) }\end{array}$ & $\begin{array}{l}\text { Erythema, bleeding in } \\
\text { attached gingiva and } \\
\text { bleeding blisters }\end{array}$ & - & $\begin{array}{l}\text { Topical } \\
\text { corticosteroids, an } \\
\text { antifungal drug }\end{array}$ \\
\hline$(17) / 2011$ & $75 / \mathrm{F}$ & - & MMP & $\begin{array}{l}\text { Ulcerative lesions of } \\
\text { the oral mucosa, } \\
\text { Erosions of the } \\
\text { mucous membranes } \\
\text { of the lip and tongue }\end{array}$ & $\begin{array}{l}\text { Linear deposits of IgG } \\
\text { in the basement } \\
\text { membrane of the } \\
\text { epidermis }\end{array}$ & $\begin{array}{l}\text { Methyl-prednisolone } \\
\text { pulse therapy at a } \\
\text { dose of } 1 \mathrm{gr} / \text { day }\end{array}$ \\
\hline (5)/2012 & $45 / \mathrm{F}$ & Positive & MMP & $\begin{array}{l}\text { Erosions lesion in } \\
\text { marginal and } \\
\text { attached gingiva }\end{array}$ & $\begin{array}{l}\text { Linear deposition of } \\
\text { IgG and C3 at the } \\
\text { dermo-epidermal } \\
\text { junction }\end{array}$ & $\begin{array}{l}\text { Topical steroids and } \\
\text { vitamin supplements } \\
\text { for one month }\end{array}$ \\
\hline$(18) / 2015$ & $42 / \mathrm{M}$ & - & MMP & $\begin{array}{l}\text { Bright red lesion with } \\
\text { diffused area of } \\
\text { desquamation and } \\
\text { erythema }\end{array}$ & $\begin{array}{l}\text { IgG immunoglobulin } \\
\text { in the basement } \\
\text { membrane }\end{array}$ & $\begin{array}{l}\text { Topical steroids } \\
\text { Kenacort }\end{array}$ \\
\hline (19)/2015 & $57 / \mathrm{M}$ & - & $\begin{array}{l}\text { Oral Mucous } \\
\text { Membrane } \\
\text { Pemphigoid }\end{array}$ & $\begin{array}{l}\text { Few bullae, erosions, } \\
\text { and } \\
\text { pseudomembrane- } \\
\text { covered erosions on } \\
\text { the right buccal } \\
\text { mucosa }\end{array}$ & $\begin{array}{l}\text { Linear band of IgG, } \\
\text { IgA, and C } 3 \text { at the } \\
\text { epithelial BMZ }\end{array}$ & $\begin{array}{l}\text { Oral prednisolone, } \\
\text { Intravenous } \\
\text { immunoglobulin } \\
\text { (IVIg) at a dose of } 2 \\
\text { g/kg/cycle }\end{array}$ \\
\hline$(20) / 2016$ & $64 / \mathrm{F}$ & Positive & MMP & $\begin{array}{l}\text { Burning sensation } \\
\text { and pain of the right } \\
\text { upper gums and } \\
\text { palate }\end{array}$ & - & $\begin{array}{l}\text { Intralesional } \\
\text { triamcinolone } \\
\text { acetonide }\end{array}$ \\
\hline (1)/2016 & $41 / \mathrm{M}$ & Positive & MMP & $\begin{array}{l}\text { Bleeding gums and } \\
\text { burning sensation on } \\
\text { gum }\end{array}$ & - & $\begin{array}{l}\text { Oral prophylaxis and } \\
\text { topical steroid } \\
\text { application for } 2 \\
\text { months }\end{array}$ \\
\hline \multirow{2}{*}{$(21) / 2016$} & $60 / \mathrm{F}$ & Positive & MMP & $\begin{array}{l}\text { Ruptured leaving } \\
\text { painful ulcers and } \\
\text { peeling of the gingiva }\end{array}$ & - & $\begin{array}{l}\text { Taper the topical } \\
\text { steroid application }\end{array}$ \\
\hline & $67 / \mathrm{F}$ & Positive & MMP & $\begin{array}{l}\text { Blisters in the mouth } \\
\text { occurring frequently } \\
\text { for } 3 \text { months. Blisters } \\
\text { ruptured to leave an } \\
\text { ulcerated area }\end{array}$ & - & topical steroids \\
\hline$(22) / 2018$ & $57 / \mathrm{F}$ & Positive & MMP & $\begin{array}{l}\text { Gingiva bled on } \\
\text { probing with no } \\
\text { attachment loss }\end{array}$ & - & $\begin{array}{l}\text { Topical corticosteroid, } \\
\text { clobeta-sol } \\
\text { propionate } 0.05 \%\end{array}$ \\
\hline
\end{tabular}

Abbreviations: DG, Desquamative Gingivitis; DIF, Direct Immunofluorescence; F, Female; M, Male.

thermore, DG is a sign of some mucocutaneous disease and proper identification will result in an accurate diagnosis and appropriate management (5). The other issue, in this case, was the negative results of DIF test that could cause misdiagnosis. These 2 issues make the diagnosis of the disease more difficult. Therefore, a second biopsy examination had to be performed to confirm the accurate diagno- sis. After prescribing topical corticosteroid and performing the precise scaling for the patients, the follow up and the healing process continued. Mignogna et al. reported that the Nikolsky's sign in $72 \%$ of patients with MMP was positive (15). Table 1 summarizes the MMP cases with Nikolsky's sign, DIF results, oral lesion, and treatment reported during 2010 up to now. 

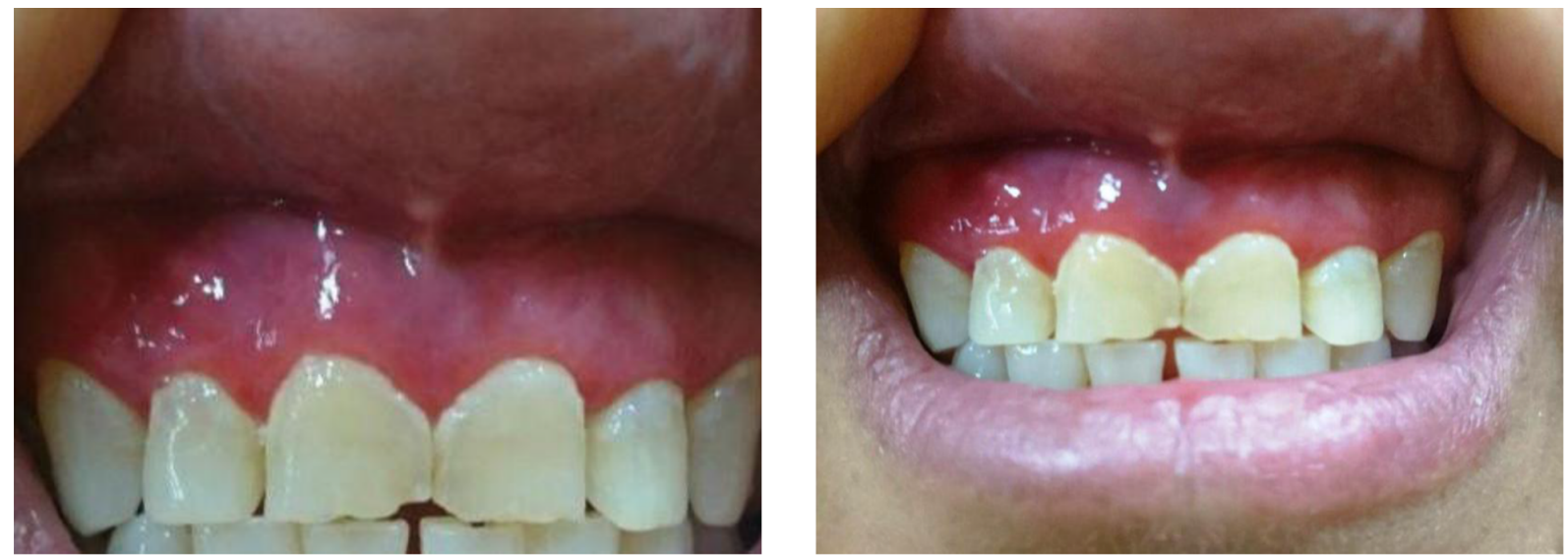

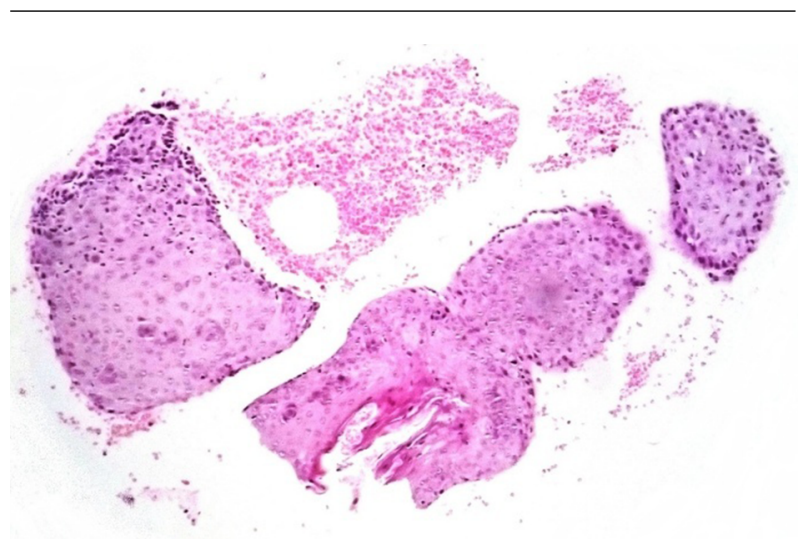

Figure 2. Microscopic view of mucosal lesion
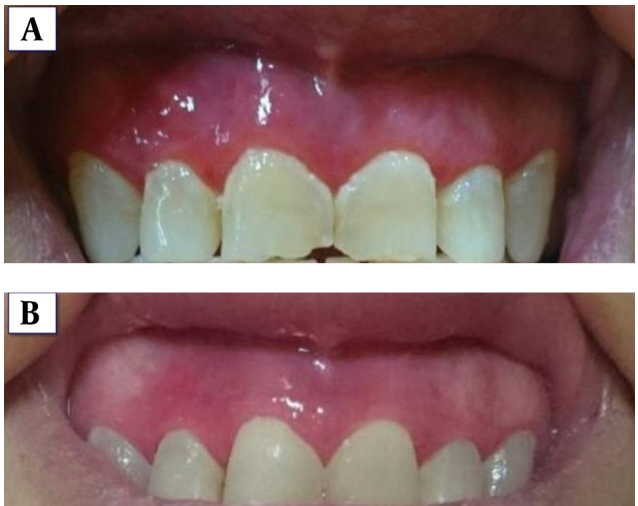

Figure 3. Comparison of the patient's gingiva before (A) and after (B) treatment

\subsection{Conclusion}

Mucous membrane pemphigoid, presenting as exclusive DG, is rare. Accurate diagnosis of the condition re- quires taking a detailed history, a complete intraoral and extraoral examination, with DIF and histopathologic studies. The gingival lesions are generally treated with topical corticosteroid therapy and improved oral hygiene measures.

\section{References}

1. Vijayan V, Paul A, Babu K, Madhan B. Desquamative gingivitis as only presenting sign of mucous membrane pemphigoid. J Indian Soc Periodontol. 2016;20(3):340-3. doi: 10.4103/0972-124X.182602. [PubMed: 27563211].

2. Al-Abeedi F, Aldahish Y, Almotawa Z, Kujan O. The Differential Diagnosis of Desquamative Gingivitis: Review of the Literature and Clinical Guide for Dental Undergraduates. J Int Oral Health. 2015;7(Suppl 1):8892. doi: 10.4103/2278-9626.163338. [PubMed: 26225114].

3. Glick M. Burket's Oral Medicine. 12 ed. USA: People's Medical Publishing House; 2015. p. 69-83.

4. Hasan S. Desquamative gingivitis - A clinical sign in mucous membrane pemphigoid: Report of a case and review of literature. J Pharm Bioallied Sci. 2014;6(2):122-6. doi: 10.4103/0975-7406.129177. [PubMed: 24741281].

5. Hasan S, Kapoor B, Siddiqui A, Srivastava H, Akhtar Y, Fatima S. Mucous membrane pemphigoid with exclusive gingival involvement: Report of a case and review of literature. J Orofac Sci. 2012;4(1):64-9. doi: $10.4103 / 0975-8844.99884$.

6. Arash A, Shirin L. The management of oral mucous membrane pemphigoid with dapsone and topical corticosteroid. J Oral Patho Med.2008;37(6):341-4. doi: 10.1111/j.1600-0714.2008.00653.x. [PubMed: 18331284].

7. Suresh L, Neiders ME. Definitive and differential diagnosis of desquamative gingivitis through direct immunofluorescence studies. $J$ Periodontol. 2012;83(10):1270-8. doi: 10.1902/jop.2012.110627. [PubMed: 22264207].

8. Neff AG, Turner M, Mutasim DF. Treatment strategies in mucous membrane pemphigoid. Ther Clin Risk Manag. 2008;4(3):617-26. doi: 10.2147/TCRM.S1140. [PubMed: 18827857].

9. Darling MR, Daley T. Blistering mucocutaneous diseases of the oral mucosa-a review: part 2. Pemphigus vulgaris. J Can Dent Assoc. 2006;72(1):63-6. [PubMed: 16480607]. 
10. Robinson NA, Wray D. Desquamative gingivitis: a sign of mucocutaneous disorders-a review. Aust Dent J. 2003;48(4):206-11. [PubMed: 14738122].

11. Saito A, Makiishi T. Chronic desquamative gingivitis and oral healthrelated quality of life. J Dermatol Case Rep. 2009;3(3):47-9. doi: 10.3315/jdcr.2009.1034. [PubMed: 21886731].

12. Gagari E, Damoulis PD. Desquamative gingivitis as a manifestation of chronic mucocutaneous disease. J Dtsch Dermatol Ges. 2011;9(3):184-8. doi: 10.1111/j.1610-0387.2010.07543.x. [PubMed: 21050381].

13. Mortazavi H, Abbasi F, Koopaie M, Esmaeili N. ELISA sensitivity in detection of autoantibodies desmoglein 1 and 3 in saliva and serum of patient with pemphigus vulgaris. Dermatol Cosmetic. 2014;5(2):69-75.

14. Bhatia P, Dudhia B, Patel PS, Patel M. Benign mucous membrane pemphigoid. J Ahmedabad Dent Coll Hosp. 2011;2(48-54).

15. Mignogna MD, Fortuna G, Leuci S, Ruoppo E, Marasca F, Matarasso S. Nikolsky's sign on the gingival mucosa: a clinical tool for oral health practitioners. J Periodontol. 2008;79(12):2241-6. doi: 10.1902/jop.2008.080217. [PubMed:19053912].

16. Orrico SR, Navarro CM, Rosa FP, Reis FA, Salgado DS, Onofre MA. Periodontal treatment of benign mucous membrane pemphigoid. Dent Today. 2010;29(7):100-2. quiz 102-3. [PubMed: 20687433].

17. Barbosa Ldo N, Silva RS, Verardino GC, Gripp AC, Alves Mde F. Mucous membrane pemphigoid with severe esophageal stricture. An Bras Dermatol. 2011;86(3):565-8. [PubMed: 21738978].

18. Abbayya K, Kadashetti V, Baad R, Lohana M. Desquamative gingivitis: A clinical sign in mucous membrane pemphigoid. European J Gen Dent. 2015;4(3):136-9. doi: 10.4103/2278-9626.163338.

19. Laureano A, Cardoso J. Unilateral oral mucous membrane pemphigoid: refractory atypical presentation successfully treated with intravenous immunoglobulins. Case Rep Dermatol Med. 2015;2015:930859. doi: 10.1155/2015/930859. [PubMed: 25785208].

20. Hasanoğlu Erbaşar GN. Localized oral mucous membrane pemphigoid: Successful treatment with intralesional triamcinolone acetonide injection. J Dent Oral Care. 2016;2(5):1-5. doi: 10.15436/23791705.16.1151.

21. Dharman S, Muthukrishnan A. Oral mucous membrane pemphigoid - Two case reports with varied clinical presentation. J Indian Soc Periodontol. 2016;20(6):630-4. doi: 10.4103/jisp.jisp_155_16. [PubMed: 29238145].

22. Capocasale G, Panzarella V, Rodolico V, Di Fede O, Campisi G. In vivo optical coherence tomography imaging in a case of mucous membrane pemphigoid and a negative Nikolsky's sign. J Dermatol. 2018. doi: 10.1111/1346-8138.14267. [PubMed: 29479786]. 